\title{
Mapping of Geospatial Information on Disasters Predicted to Occur in Wetland Areas of the Shonan Region
}

\author{
Kuniaki Isobe $^{\mathrm{a}, *}$, Toshiro Sugimura ${ }^{\mathrm{a}}$ \\ a Nihon University, k.trend@jcom.home.ne.jp, sugimura.toshirou@nihon-u.ac.jp
}

Keywords: Satellite image, QuickMap (Jinsokusokuzu), Temporal analysis

\begin{abstract}
:
Ground damage, such as liquefaction events, occurred in the Kanto region during the Great East Japan Earthquake on March 11, 2011. Similar disasters can be expected to occur in the future. Disaster prevention and preparedness plans have been developed by municipal governments based on the principle of Jijo (self-aid), Kyojo (community assistance), and Kojo (government assistance). With national land information, including the latest satellite images and Jinsokusokuzu (QuickMap) prepared during the Meiji period, being compiled, consolidated and analysed, it is now expected that such national land information can be utilized in the field of disaster mitigation.
\end{abstract}

According to an old map, the old Kugenuma Lake used to be spread in the southeast of the city of Fujisawa, which is currently located in the dune lands in the Shonan region. This area is composed of sandbanks formed by the Hikichi River and the Sakai River. From the synthetic images based on satellite images and QuickMap, among other things, it is expected that a disaster may cause serious damage in areas of weak ground conditions along the old river ways and the brinks (cliffs) of the old Kugenuma Lake as they have been rapidly converted into residential areas (Figure 1). The evacuation map prepared based on this assumption indicates that nearby tsunami evacuation buildings should serve as an emergency evacuation centre for evacuees (Figure 2). In the vicinity of these emergency evacuation centres, however, there are various areas that may become impassable for evacuees and emergency vehicles due to the potential collapse of stone walls and utility poles, among other things.

From the synthetic images based on geospatial information, it is possible to identify areas prone to liquefaction in regions whose past land cover is related to water (Figure 1). The evacuation map, which has been prepared based on the reading of hazard maps and the results of our field investigation, has exposed a number of issues facing disaster-predicted areas (Figure 2). As a result, it is recommended that 1 ) a community association ensure to always keep evacuation routes operable and clear of any obstructions that may impede evacuation and 2) to conduct an emergency evacuation drill in different seasons and time zones. It is also essential to ensure that a community will develop its own technical capability and autonomous community-based capability to provide relief to its own community members through Kyojo.

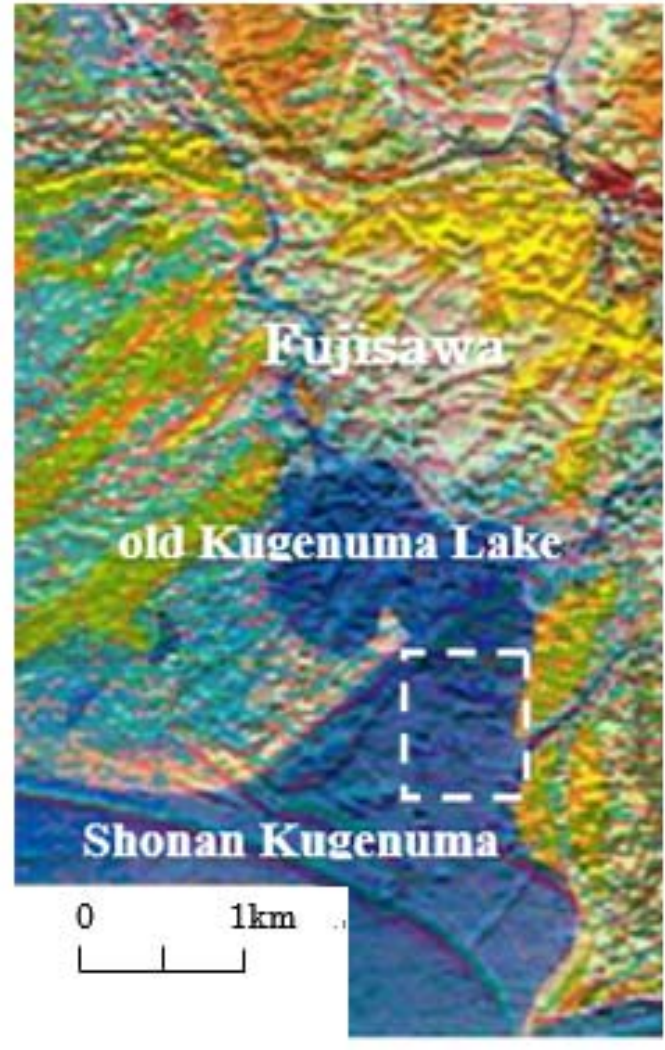

Figure 1. Synthetic images based on satellite images, old maps, and Jinsokusokuzu (QuickMap)

Acknowledgements: In the synthesis of images, the author received cooperation from Yoshihiko Akiba, Master of Science, at Asia Air Survey Co., Ltd., and from Risako Ishida, Master of Engineering, at Fujitsu Frontech Ltd. The author deeply appreciates their cooperation. 


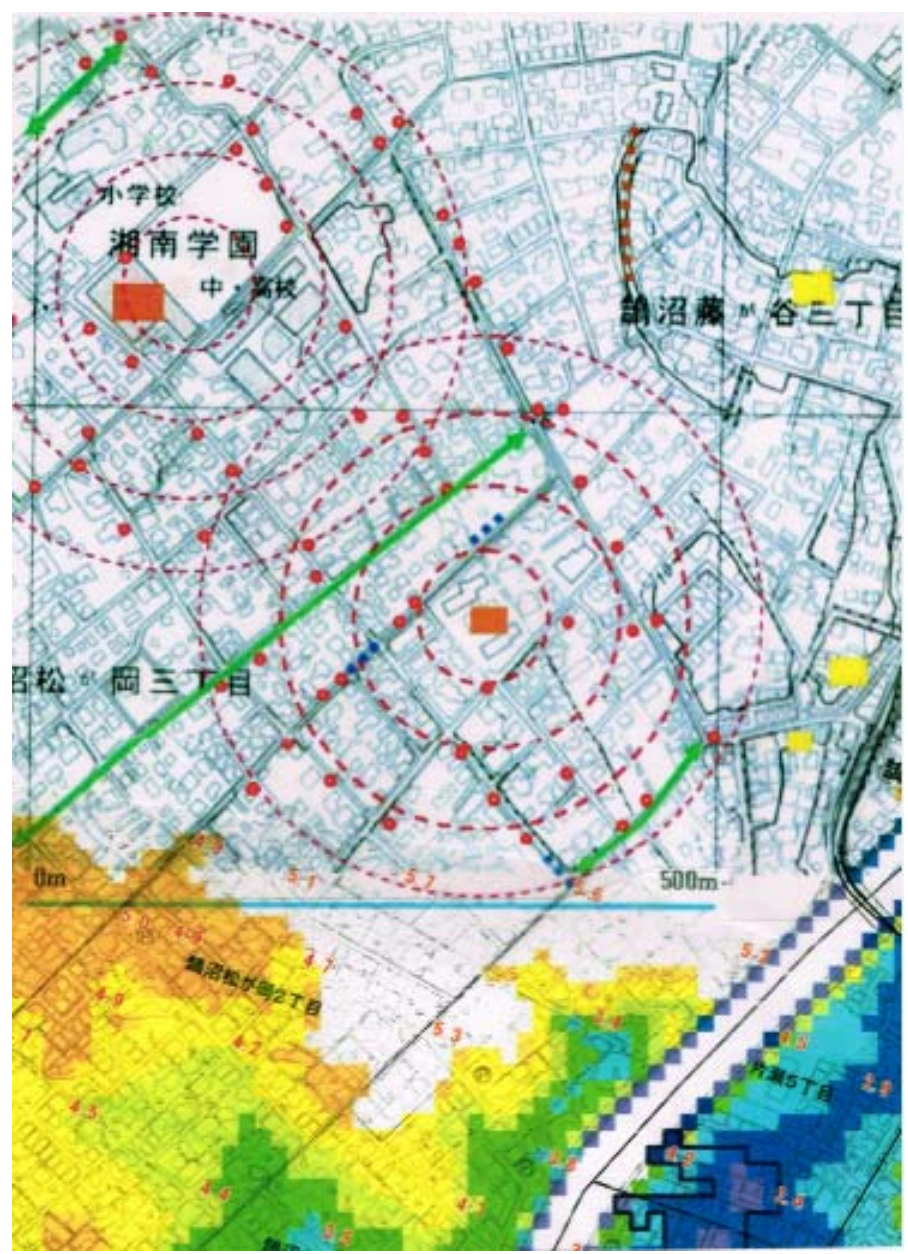

Low-altitude temporary shelter

Evacuation destination of the high altitude (high ground)

Social infrastructure that may impede passage if it collapses

Utility poles with transformers and inclined utility poles

...... Stone walls about to collapse \#nn+n a cliff that is likely to collapse

Broken-line concentric circles: plotted every 50 meters from emergency evacuation center

$\longrightarrow$ Road where traffic volume is expected to increase

Expected depth of inundation in the tsunami inundation hazard map

Figure 2. Potential tsunami inundation areas and primary causes of obstructions that may impede passage in the vicinity of emergency evacuation centres (Shonan Kugenuma) 